\title{
TEACHERS NEED SCIENTIFIC AND EXPERIENTIAL KNOWLEDGE ON LEARNING SUPPORT: RECOMMENDATIONS FOR A TEACHER EDUCATOR
}

\author{
M. M. Oswald \\ Department of Educational Psychology \\ Stellenbosch University \\ Stellenbosch, South Africa \\ e-mail: mmoswald@sun.ac.za
}

\section{ABSTRACT}

This article discusses teachers' lack of scientific (theoretical) knowledge on learning support in the classroom. This was one of the key findings of a basic exploratory qualitative study conducted in a South African secondary school. The study employed a Cultural-Historical Activity Theory (CHAT) framework. Six teachers from the school took part in the research. The results underscored their lack of scientific knowledge on learning support, confirming a perceived gap between theory and practice, contrary to CHAT's take on the matter. The discussion highlights the value of scientific knowledge for the teacher and offers a number of recommendations for the work of the teacher educator.

Keywords: Secondary teacher education, inclusive education, learning support, CulturalHistorical Activity Theory, scientific knowledge, experiential knowledge

\section{INTRODUCTION}

The inclusion of initial teacher education in higher education reflects a belief that becoming a teacher involves more than learning skills on the job. Teacher education has, however, struggled for decades to define the theoretical dimension of its programmes, as well as to determine the nature of the association between universities and schools in teachers' learning (Ellis, Edwards and Smagorinsky 2010). Previously, the assumption was simply that theory was learned in higher education and put into practice in school. This was also the traditional approach to teacher education programmes in South Africa. Despite the fact that this is now considered outof-date, the model is still in use in certain higher education institutions. Recently several teacher educators in inclusive education have expressed unease with the traditional theory/practice divide and have made concerted efforts to address this in their courses (e.g. Peters and Reid 2009; Walton and Lloyd 2012). McIntyre $(2009,603)$ argues that there is irrefutable evidence that "a theory-into-practice approach simply does not work" when implementing inclusive education in a school. Inclusive education can disrupt the status quo in schools where ability 
labelling and the categorization of learners (based on outdated theoretical approaches and practices) are still regular practices. In light of this, it is critical that the theory/practice divide be addressed within the context of inclusive education (McIntyre 2009).

Theoretical learning is certainly viewed as a prerequisite for practical learning, but the assumption is often made that the transfer between theoretical and practical learning will happen automatically. However, a report by the Organisation for Economic Co-operation and Development (OECD) shows that this process is not as self-evident and uncomplicated as expected. The report highlights the need for teacher education to be better adapted to teachers' changing roles, to rethink the approach to practical learning in schools, and to be better attuned to the interconnections between pre-service teacher education and induction into the workplace, as well as to the continued professional development of teachers (Jahreie and Ottesen 2010).

The most recent South African Higher Education publication on teacher education, "Minimum Standards for Teacher Education Qualifications" (MRTEQ), underscores the importance of "inter-connections between different types of knowledge and practice, as well as the ability of teachers to draw reflexively from integrated and applied knowledge, so as to work flexibly and effectively in a variety of contexts" (DHE 2011, 7). "Integrated and applied knowledge" points to "fusing together and expressing different types of knowing in the moment of practise" (DHE 2011, 7). The teacher should be able to successfully navigate the dynamic interplay between educational theory (scientific knowledge) and practice. Teacher educators should therefore build a strong link between taught modules (theory) and work-based learning (practice) in local schools to allow student-teachers to gain maximally from teacher education. Simultaneously, in-service teachers are expected to be conversant with the more recent theoretical initiatives concerning learning support, allowing them to develop a synergy between the two settings of student learning. The findings of this study pointed to the contrary: theoretical knowledge on learning support in the classroom was missing from the repertoire of the participating teachers.

In South Africa learning support is provided within an inclusive education system. Education White Paper 6: Special Needs Education: Building an Inclusive Education and Training System of 2001 (DoE 2001) formalized South Africa's particular approach to inclusive education. The White Paper adhered to the broader equity agenda of inclusive education as a systemic process of overcoming barriers to learning and development, highlighting that all learners can learn but that they all need support to accomplish this successfully. Subsequently, the White Paper called for enabling educational structures, systems and learning methodologies to meet the learning needs of all learners. The classroom teacher is singled out as the first and most important link in the chain of support to ensure quality learning for learners. For teachers 
to meet these conditions, changes in attitudes, as well as in behaviour, teaching methods, curricula and the environment are suggested. Several additional support processes and procedures have been recommended in the White Paper. These include a School Based Support Team (SBST) and a District-Based Support Team (DBST). The SBST involves mainly teachers at the particular school, but suitable professionals from the community can also be co-opted as members, while the DBST consists of different support professionals (e.g. psychologists, learning support educators and curriculum specialists) who provide support to all the schools in the jurisdiction of the district. Different types of schools are also recommended as part of the support network. Special schools as Resource Centres (SSRC) accommodate learners with a high intensity support needs, while Full-Service Schools (FSS) are available for learners with a moderate intensity of support needs.

However, the reality is that several complex challenges remain in closing the gap between the idealism of policies and the successful implementation of inclusive education in South Africa (Engelbrecht et al. 2016). The above "support" schools are not available in all the provinces of South Africa, and where available, are only for a limited number of learners. Special placement options in particular are sparse for secondary school learners, and in many instances learners experiencing barriers to learning are accommodated in mainstream schools (Nel and Grosser 2016). More recent education documents also emphasize that placement in special and full-service schools should only be seen as a last resort (e.g. DBE 2014). Often the parents of these children also prefer that they attend mainstream schools. Only in certain secondary schools will a learning support teacher be available to assist learners, either on an individual basis or within small groups. This means that classroom teachers in mainstream schools would need to increase their capacity to respond meaningfully to learner diversity. They would have to adjust to the support needs of their learners, rather than expecting the learners to adjust to a system which is not responsive to their needs. Teachers cannot work using a onesize-fits-all approach. Instead, they need to start from the base of knowing each learner well and building on the individual's particular level of knowledge (Oswald 2010). Current policy documents in South Africa advocate curriculum differentiation as the way to make inclusion a reality in all classrooms (DBE 2010; 2011).

This focus of this article is on classroom teachers' lack of scientific (theoretical) knowledge on learning support in a secondary school. This was one of the key findings of a basic exploratory qualitative study into teachers' understandings and practices of learning support in the classroom. The article will first describe the use of Cultural-Historical Activity Theory (CHAT) as a theoretical lens, followed by the methodology, a review of the findings, and the discussion and conclusion. 


\section{THEORETICAL LENS}

Cultural-Historical Activity Theory (CHAT) strongly rejects the dualistic distinction drawn between theory and practice. Researchers such as Ellis, Edwards and Smagorinsky (2010), working within CHAT, have extrapolated Vygotksy's genetic model to examine teacher education. They claim that CHAT offers a powerful theoretical lens on the professional development of teachers. Grounding professional development within CHAT seems appropriate: all professional development theories seem to share with CHAT the concept of development due to social interaction. Vygotsky's theory of development, however, differs from other theories in as much as it maintains that all higher psychological functions themselves are inherently social (Eun 2008).

CHAT views the learning of teachers as situated. Teachers learn by engaging with resources which are stretched over specific settings (such as lecture halls and schools) which are in a dialectical relationship. Teacher learning and development are shaped through the dynamics of activity, in which contextual and individual forces, following the logic of unfolding activity processes, are absorbed and transformed (Stetsenko and Arievitch 2004). Thus, the dialectical relationship between theory and practice in teacher learning is resolved as human activity in specific settings. This relationship should form the basis for teacher education (Smagorinsky, Cook and Johnson 2003).

Vygotsky emphasizes the interdependence in the development of scientific concepts (theory) and spontaneous concepts (derived from practice and experience). Scientific concepts are systematically organized bodies of knowledge which are flexible in the sense that they can be applied across different settings. They are embedded in cultural systems and acquired in formal learning systems, including in academic curricula (Ball and Wells 2006; Blanton, Moorman and Trathen 1998). In the context of this study, scientific knowledge for learning support would be associated with pedagogical knowledge and specialized content knowledge. Student-teachers should gain knowledge and skills on managing learning diversity in the classroom, identifying and addressing barriers to learning and on curriculum differentiation (DHE 2011). In contrast, spontaneous concepts are more context-bound and less flexible. They develop informally in the everyday events of teaching practice (Blanton et al. 1998). Vygotsky contends that "the 'empirical' worldliness and flux of the spontaneous concepts preserves a richness that is critical for the appropriation [internalization]" of scientific (theoretical) concepts (Ball and Wells 2006 191), but is less responsive to being abstracted in new situations (Smagorinsky et al. 2003). Thus, knowing with regard to learning support cannot be reduced either to the acquisition of theoretical knowledge or to personal knowledge gained through 
experience in teaching. "Instead, knowing is considered as a recursive yet expanding cycle of practical activity and theoretical reflection as the [teacher-]learner engages in a more complex yet interconnected system of domain specific conceptions" (Ball and Wells 2006, 190). This implies that any separation of theory and practice is artificial and misses the point of how teachers learn. We need to recognize teaching as a complex and difficult occupation which cannot rely exclusively on experiential knowledge. Scientific theory makes possible the achievement of a deeper and more integrated understanding of practice, enabling teachers to reflect on challenges beyond their range of experience (Smagorinsky et al. 2003). Scientific knowledge teaches the why, helping the teacher understand why one technique works where another fail. In doing so it helps to set strategy.

Particularly important for teacher learning and development is the emphasis on conceptual learning that is evident in CHAT thinking on teacher education. Smagorinsky et al. $(2003,30)$ contend that "the problem with teacher education is not too much theory [as often indicated by practitioners], but too little concept". It is worth quoting Warford $(2011,253)$ on this issue:

"Failure to achieve this level of engagement only serves to perpetuate the dominant transmission approach of cramming curricular content around clusters of micro-genetic interventions. Like skipping pebbles on the surface of a pond, pouring on the prescriptions, the potpourri of 'practical tips' seem to generate momentum, then ultimately sink into the abyss."

Teachers need conceptual knowledge in order to establish a meaningful relationship between theory and practice. However, it is not easy to achieve a unified concept. The development of a concept follows a twisting and gradational path as teacher-learners gain new knowledge and experiences across different contexts (Smagorinsky et al. 2003). This further acknowledges a dialectical relationship between theory and practice. Vygotsky (1987) maintains that "instruction in principles alone will not result in the development of a concept, rather, knowledge of abstracted governing rules [theory] must come in conjunction with empirical demonstration, observation, or activity" (Smagorinsky et al. 2003, 7). In this study, the teachers needed to grasp the broad philosophical underpinnings in which inclusive education and more recent approaches to learning support are embedded, in order to understand and embrace the notion of themselves as central to the support network for all learners.

Warford (2011), however, warns that the blending of theory and practice does not happen automatically. For actual development to occur, it should be carefully mediated in the education of teachers. Given a CHAT framework, the norm for the teacher educator should be to explicitly meld the scientific discourse of the university lecture hall with the experiential discourse of local classrooms. Should this not happen, the result might be cognitive dissonance, as "teachers 
unfamiliar with the more powerful discourse of the academy are likely to feel alienated by it and unwilling to test and develop the theories carried by it in their practices" (Edwards 1996, in Warford 2011, 253).

\section{RESEARCH DESIGN AND METHODOLOGY}

For this study, I employed an exploratory qualitative method, embedded in an interpretive research paradigm, to investigate classroom teachers' learning support practices in a mainstream secondary school. I used convenience sampling in the selection of the school. The school is well-known to me. It is well established, has an excellent track record and maintains an open-door policy, welcoming children from more than 20 primary schools from diverse contexts, as well as those with disabilities and learning challenges. Once the principal and staff had indicated their willingness to share in the project, I sought and obtained ethical clearance from the Research Ethics Committee at the relevant university. The Western Cape Education Department also approved the project. The following ethical principles were adhered to: autonomy and respect for the dignity of persons; non-maleficence (protecting research subjects against harmful or negative influences); beneficence (maximizing the benefits of the research for the participants); and justice (treating them with fairness and equity during all the stages of research) (Wassenaar 2006).

The selection of the teachers was based on their willingness to take part in the research. The participants were from different departments in the school. This ensured a greater diversity of subjects and perspectives. Five female teachers agreed to act as participants, but only one male teacher was prepared to join in the project (See Table 1 for their biographical information).

Table 1: Biographical information of participants (at time of research)

\begin{tabular}{|c|c|c|c|l|l|}
\hline Participant & Gender & Age & Experience & Post level & \multicolumn{1}{|c|}{ Subjects } \\
\hline Participant 1 (P1) & F & 24 & 2 years & I teacher & $\begin{array}{l}\text { Learning support, Counselling, Life } \\
\text { Orientation, English. }\end{array}$ \\
\hline Participant 2 (P2) & F & 26 & 3 years & I teacher & $\begin{array}{l}\text { Accountancy, Mathematics, } \\
\text { Economic and Management } \\
\text { Sciences. }\end{array}$ \\
\hline Participant 3 (P3) & M & 53 & 11 years & I teacher & Tourism, Social Sciences. \\
\hline Participant 4 (P4) & F & 28 & 3 years & I teacher & Social Sciences, Geography. \\
\hline Participant 5 (P5) & F & 51 & 28 years & I teacher & Mathematics. \\
\hline Participant 6 (P6) & F & 39 & 16 years & Vice-principal & $\begin{array}{l}\text { Accountancy, Economic and } \\
\text { Management Sciences, } \\
\text { Mathematics. }\end{array}$ \\
\hline
\end{tabular}

The data was generated using an open-ended questionnaire completed by all the teachers, six individual interviews, and a focus group interview with all the participants. The latter served as a form of member checking to validate the findings from the individual interviews and the 
questionnaires. For the semi-structured individual interviews, I adopted a flexible interview schedule limited to the following broad-based question: Please tell me about support for learning in your classroom. The open-ended questionnaire asked the following two questions: 1) Please describe in detail your understanding of what learning entails; and 2) Please describe in detail your view on learning support in the classroom. The open-ended questions in the focus group interview were developed in response to the findings of the individual interviews and open-ended questionnaires. The following broad questions directed the focus group discussion:

- $\quad$ Please describe your theory and practice regarding learning support in your classroom.

- How would you explain the culture in your school?

- Can you please explain your understanding of curriculum differentiation?

- $\quad$ Please discuss the role that reflection plays in your practice?

Thematic analysis, a method to identify and analyse patterns (themes) within data, was employed to analyse the data. Braun and Clark $(2006,77)$ claim that it "offers an accessible and theoretically flexible approach to analyzing qualitative data". They further explain that "a theme captures something important about the data in relation to the research question, and represents some level of patterned response or meaning within the data set" (Braun and Clark 2006, 82). The data corpus - that is, all the data collected during the research activity - revealed several themes of importance relating to learning support in the particular secondary school. As noted above, the article only discusses the findings from the particular data set which highlight the participants' apparent lack of scientific knowledge about learning support. This presented as a strong theme in the data corpus.

\section{PRESENTATION OF FINDINGS}

From the data set, three subthemes emerged which underlined the teachers' apparent lack of theoretical knowledge about learning support. These will be discussed under the following headings: navigating the transition between university and school; the positioning of scientific knowledge in the school; and perspectives on learning support.

\section{Navigating the transition between university and school}

The data showed that for the participants the transition from university to school represented a move away from theory to practice, in the sense that theory was learned at university and had to be translated into practice in school (where possible). They found this process 
particularly challenging. The following examples from the data echo this. P1 experienced the theoretical "injection" at university as wonderfully rich and overwhelming, to such an extent that she was unable to internalize everything: "From there you have to walk into class and be able to apply it in practice; it is very difficult”. She struggled with this, despite already being a few years into her teaching career. While she recognized some points of tangency between scientific knowledge and the spontaneous knowledge acquired from "being in front of a class," in general teaching for her preserved a dualistic relation between theory and practice (Smagorinsky et al. 2003). Neverthless, she had kept her academic books and said she would return to the theory as time allows. She did acknowledge teaching "as a constant process of learning". This resonates with P3's view of it as a profession which requires continuous development: "If you stop growing you die. A tree that stops growing will eventually die. You don't want a child in an environment where he has to work with somebody who is busy dying."

Among his other duties, P3 was placed in charge of students from our faculty during their period of "practical" learning in the school. He saw this as a valuable learning opportunity for both students and teachers. He observed how the students learning in the school applied the theory acquired at university, and was eager to smooth the way for them, believing that the successful application of scientific knowledge was "one of the biggest challenges of beginner teachers." At the same time, he felt the teachers could learn from the students, as they were " $a$ source of new research in education".

In both the above examples a certain schism between theory and practice was evident. Scientific knowledge, acquired at university, was applied in the school. Even P3, who had undergone no formal teacher training, acknowledged the value of such knowledge in the classroom. He saw the application of such knowledge as challenging, especially for beginner teachers who struggled to bridge the gap between theory and practice. He based his own teaching (and support of learning) in the classroom on one particular book, which however was of more inspirational than academic value.

The data also revealed a lack of opportunities for the staff to engage with theoretical advances (associated with the university) relating to learning support. Especially given their open school policy, the teachers needed additional scientific knowledge on such support. An increase in learner diversity, coupled with the need to support all the learners, made the teachers even more aware of the lack of scientific knowledge in their repertoire. P4 suggested that the principal could do more to help the staff address the needs of learners more effectively. She felt that the staff would do better by formalizing opportunities to learn, both from other experts and from one another. The shortage of time was always the culprit; nevertheless, she believed that, were these opportunities to be formalized, the teachers could only benefit: 
"We have so many children with different challenges in our school and we all need more knowledge. We had one session as a group on ADHD and it was wonderful to see how we all learned from one another. I feel that too many children get labelled because we do not have sufficient knowledge about learning challenges. Teachers seldom do extra research. But if we can have a presentation from time to time, that will be wonderful. I also think that the teachers enjoy learning from one another."

Her comment highlighted the need for additional knowledge on learning support in the school. To do their work well, the teachers needed to keep up with theoretical advances. She also foregrounded the importance for teachers of learning from experts and being active constructers of knowledge in collaborative relationships.

\section{The positioning of scientific knowledge in the school}

The data revealed a dearth of scientific knowledge among the participants. This was evident in their struggle to use theoretical concepts accurately, such as "dynamic assessment" and "learning style". They failed to agree on the meaning of "learning style" or "preference". One way of defining "learning style" is as "cognitive, affective and psychological behaviour that serve as relatively stable indicators of how learners perceive, interact or respond to the learning environment" (Gilbert and Swanier 2008, 30). P1 tried to explain the concept of a learning style during the focus group interview: "You have to incorporate all the different learning styles. They have to be accommodated on a visual level but they also have to be actively involved in the assignment." In contrast, P6 wrongly interpreted the notion of learning style as the skill to learn effectively: "It is a pity that the children who need support do not have learning styles and it becomes the task of the teacher to force her own learning style on the learners. Learning support should happen in primary schools to prevent these problems in the secondary school. At the time that they enter the secondary school they should have learning styles." Thus, there was no clear consensus on the interpretation of a learning style or preference. This was a disconcerting finding.

A more readily accessible way of engaging with scientific knowledge was by keeping abreast of new policy material. P2, however, made it clear that they were not really "into documents and stuff'. In this way, they forfeited the chance to critically engage with the recent theoretical developments favoured by the education department.

The teachers also showed an unwillingness to engage with theoretical concepts. They resisted all my attempts to entice them into using such ideas during the different interviews. Instead, they fell back on spontaneous knowledge garnered during their practice in the classroom. One such example came from my interview with P6, who explained that the school 
was well-known for accommodating all learners, including those in need of special attention. "We have crossed the bridge long ago. We have accepted that they are part of society." Despite my attempts to offer "inclusive education" as a possible concept for what they were practising at the school, she resisted it.

The notion of "differentiated teaching" also challenged the teachers. They had never come across it, despite prominent discussions in the educational literature on how to support a diverse group of learners in the classroom. In the words of P3: "Okay, how do they define it, the term? It sounds like a steak that has been burnt. How do they define it in terms of learning support in a school, how do they define it?" As noted above, current education documents in South Africa view curriculum differentiated as a way of supporting all learners in the classroom (DBE 2010; 2011). Such an approach assumes that learners come to the class with different levels of readiness, interests and learning profiles. To maximize learning, teachers need to modify the curriculum, their teaching methods, their teaching and learning resources, activities and assessments in order to make them individually relevant (Walton 2012). P6 suggested that in practice differentiated teaching would be difficult. "We do not know the children to that extent. Okay, unless they were tested and identified [by experts], you don't know them." The teachers were unaware of the different strategies available to identify the strengths and abilities of their learners in class and to pave the way for differentiated teaching.

The participants were informed about the need for and value of reflection on their teaching. Time for reflection was limited, however, as their work was "exhausting and demanding" and "left little time for reflection because [they] are often on survival mode" (P4). They saw reflection as a way to self-knowledge and development as teachers, but theoretical reflection, in the sense of demonstrating how the theory could help them understand their practice in the classroom and vice versa, was never part of the discussion. From the data, it was clear that scientific knowledge on learning support was not given a high priority, despite the school's self-professed focus on accepting and supporting all learners.

\section{Perspectives on learning support}

As previously noted, educational policy in South Africa underscores the values and practices of inclusive education. It views support for learning as integral to schooling, with supportive education taking a central place in the classroom (Bouwer 2016). This means that schools may need to increase their capacity in order to respond meaningfully to learner diversity. The school community as a system needs to resolve problems and work actively towards enhancing the success of all learners (Johnson and Green 2007). Teachers need to be willing to take a key part in support, to accept the responsibility for differentiating the curriculum for particular learners 
or groups, and to be aware of the many factors which may influence learning success.

While educational policy advocates the values, principles and practices of inclusive education, the data showed that the teachers struggled with integrating the notion of learning support as part of their everyday practice in the classroom. It was still associated with experts in the area of learning support (such as P1 in the school) and with tutors who privately helped with certain subjects through extra classes after school. However, such services were not free and were therefore not open to all learners. This is a complex issue, but one which needs urgent attention. P1 suggested that having to think about learning support in terms of 40 learners in the classroom was a new departure. "I see this as a particular challenge. More effort will have to be put into your planning. You have to think further in terms of how to actively support the learning of all the learners but also the particular child who struggles. Teachers will need the necessary tools to assist them in thinking differently about learning support."

Additionally, they maintained that the demands of the curriculum, together with time constraints, their own lack of knowledge, and overcrowded classrooms all acted as barriers to meaningful support in the classroom. "They have to get the necessary support outside the classroom because there is just not enough time during school hours, otherwise they will have to drop the subject" (P5). P4 suggested that the teachers tended to label children unnecessarily, since their workload did not allow them the time and energy for research. In order to effectively support diversity in their classrooms, they also needed more knowledge about certain challenges such as ADHD and about particular disabilities. P2 also highlighted the "wide spectrum of learners with differing abilities" they had to accommodate in their classrooms. She struggled to strike a balance between the time spent on those with high ability and those who struggled to master even basic concepts. This was especially difficult in larger classes. Apart from the important contribution already made by the learning supporter in the school, they also proposed bringing in assistants for the larger classes as an added means of support.

From the above, it is evident that the teachers need to rethink their position in the learning support network. Knowledge of recent developments in research on learning support and in educational policies could help them to address this challenge, as well as assist in more effective management of the barriers to learning in the classroom.

\section{DISCUSSION AND CONCLUSION}

This article grew out of an investigation into secondary teachers' knowledge and practices concerning learning support in the classroom. The findings of the study highlighted a lack of scientific concepts about such support. The research was conducted from a CHAT perspective which supported a dialectical view on scientific (theoretical) and spontaneous knowledge in 
initial and further teacher development. It is important to note that the data was generated using a small exploratory qualitative approach, with six teachers as participants. As is the case in smaller qualitative studies, the generalizability of the findings is debatable and should be considered with all the necessary care.

As previously noted, the research school was known for its open policy on the admission of learners. This was best explained by P6: "We sometimes think that we are a special school. The community sees us as such. They see that we take the students who struggle to learn. Where will the children go if we are not prepared to help them?" The study, however, found that, despite the participating teachers' goodwill towards their learners and their concerted efforts to support their learning, they were not conversant with recent theoretical innovations in learning support as embedded in an inclusive education approach. They seemed to adhere to the outdated notion of a theory/practice divide, but nevertheless recognized the value of continuous professional development and reflection, albeit without acknowledging the dynamic interplay between theoretical knowledge and knowledge gained from practice.

For me as teacher educator, the findings of the study were worrying. Given the dialectical view on theory and practice (acting/doing) adopted for this article, the teachers' limited theoretical knowledge on learning support would play out in their everyday actions in their classrooms. This implied that student-teachers, doing their learning period in the school, could experience a dissonance between what they have learned at university and what they encounter in the actions of classroom teachers in the research school (and most likely in other partnerships schools where student-teachers are placed for their school-based learning).

The findings left me with several questions about my own role in preparing teachers to accept ownership of all the learners in their classroom, to recognize their unique learning needs, and to be willing to stay abreast of all theoretical advances based on sound research, since these would directly impact what they would be "doing" in their classrooms. Teachers "need access to the disciplinary system of meaning as a condition for using knowledge in contextually specific applications" (Wheelahan 2008, 6). In this way, scientific knowledge supports the metacognitive thinking processes of teachers, allowing them to generate strategies to support learning in the classroom and to determine why and when to apply a particular strategy.

Given the research findings and the relevant literature, what insights have I gained which could inform my practice as a teacher educator? How will these assist in the practice of learning support in mainstream schools? The findings of the study, coupled with CHAT's dialectical relationship between theory and practice, strengthened my conviction that teacher educators need to "face both ways" in the curriculum - teaching their students to move seamlessly from theory to practice and from practice back to theory (Wheelahan 2008, 6). My first insight was 
that this would place particular demands on teacher educators, as student-teachers would have to be given adequate practical and theoretical knowledge, underpinning practice "as the basis for integrating and synthesising each" (Wheelahan 2008, 7).

The second lesson I learned was related to the first, and here I drew on Sannino (2010), working within CHAT, who warned that the move from the "abstract notions of pupils taught at the university to real teaching experiences in school" cannot be taken for granted. It "represents a critical phase and a learning challenge in the professional development of teachers" (Sannino 2010, 146). Teacher educators need to identify the level of actual development of both pre- and in-service teachers within their ZPDs and then actively blend them with the larger story of theoretical advances in the field of education, carefully mediating them to knit both scientific and spontaneous knowledge into their own professional narratives (Warford 2011). Unless this is achieved, an "untenable and awkward rift between the academy and the field" may occur (Warford 2011, 253), one with the potential to widen the "language difference" between university and school.

The third insight I gained was supported by the Vygotskian literature on teacher learning. Teacher educators need to be aware of the importance of mediating conceptual and systemic knowledge during both pre- and in-service training. Warford (2011) dismisses mere factcramming, arguing for a deeper conceptual level of processing and a systematic analytical control of scientific knowledge to allow for a meaningful relationship between scientific and spontaneous knowledge. As shown in this study, "the gravitational pull" of spontaneous knowledge gained in the everyday teaching practice can "inhibit conceptual maturation" (Warford 2011, 257). Thus, teachers often need both to relearn well-known scientific concepts and to confront new concepts. However, the cognitive dissonance arising from the latter may spawn renewed energy and bring welcome changes in practice.

My findings confirmed that opportunities for reflection are limited in schools, because of time constraints, the demands of the curriculum, and the expense of energy in daily survival. Nevertheless, as acknowledged by the teachers themselves, reflection is critical for development and growth. Theoretical reflection, however, was not a point of discussion and seemed absent in the research school. Therefore, the fourth lesson pointed to the importance of both teacher educators and pre- and in-service teachers agreeing that reflection in teaching should be governed by a conceptual framework (Warford 2011). In the lecture hall, this should be modelled and instilled as non-negotiable. In schools, teachers should be allowed the chance to reflect as a team on their practice within a well-established conceptual framework.

The fifth insight I gained highlights the role that schools can play in organizing themselves as learning communities. Collaborative learning can be a valuable tool in the self-development 
of teachers (Putnam and Borko 2000). The scope of this article did not allow for a discussion on the extensive body of literature on "schools as learning communities", but developing schools as learning communities offers teachers the opportunity to engage with scientific theories on learning support in the classroom. This could be accomplished by inviting experts or by the teachers themselves, acting as a team, discussing recent policy developments and research initiatives on learning support.

My final insight resonates with the previous one. It was particularly important for the research school, but could also be applied to other secondary schools. The expectation in the Education White Paper 6 (DoE 2001) is that each school should have a School Based Support Team (SBST). The primary function of such a team would be to establish a properly coordinated learner and teacher support service which could liaise with the relevant District Based Support Team (DBST), with consultants from the community and with parents. The composition of such a team would depend on the size of the school, its needs, and the number of teachers available. In the research school, a SBST could have eased the task of the learning support teacher, while also contributing to the continuous development of the teachers as learning supporters. Such a team could have initiated a development of the school as a community of learning, fostering opportunities for collaborative learning and problem-solving and the facilitation of support for both teachers and learners.

The above discussion was stimulated by my response to the findings of the study a developed within a CHAT framework. The findings strengthened my resolve when planning curricula for my modules in future to seriously explore CHAT's focus on a dialectical relationship between practical activity and theoretical reflection.

\section{ACKNOWLEDGEMENT}

This research was supported by the Fund for Innovation and Research in Learning and Teaching (FIRLT), Stellenbosch University.

\section{REFERENCES}

Ball, T. and G. Wells. 2006. Walking the talk: The complexities of teaching about teaching. International Journal of Teaching and Learning in Higher Education 18(3): 188-203.

Blanton, W. E., G. Moorman and W. Trathen. 1998. Telecommunications and teacher education: A social constructivist review. Review of Research in Education 23: 235-275.

Bouwer, C. 2016. Identification and assessment of barriers to learning. In Addressing barriers to learning: A South African perspective, ed. E. Landsberg, D. Krüger and E. Swart, 45-60. $3^{\text {rd }}$ Edition. Pretoria: Van Schaik Publishers.

Braun, V. and V. Clark. 2006. Using thematic analysis in psychology. Qualitative Research in Psychology 3(2): 77-101 
DBE see Department of Basic Education

Department of Education. 2001. Education White Paper 6 (Special Needs Education): Building an inclusive education and training system. Pretoria: Government Printer.

Department of Basic Education. 2010. Guidelines for inclusive teaching and learning. Pretoria: Government Printer.

Department of Basic Education. 2011. The National Curriculum Statement Grades R-12. Pretoria: Government Printer.

Department of Basic Education. 2014. National strategy on screening, identification, assessment and support. Pretoria: Government Printer.

Department of Higher Education. 2011. The Minimum Requirements for Teacher Education Qualifications. Pretoria: Government Printer.

DHE see Department of Higher Education

DoE see Department of Education

Ellis, V., A. Edwards and P. Smagorinsky. 2010. Introduction. In Cultural-historical perspectives on teacher education and development: Learning to teach, ed. V. Ellis, A. Edwards and P. Smagorinsky, 1-10. London: Routledge.

Engelbrecht, P., M. Nel, S. Smit and M. van Deventer. 2016. The idealism of education policies and the realities in schools: The implementation of inclusive education in South Africa. International Journal of Inclusive Education 20(5): 520-535. Doi: 10.1080/13603116.2015.1095250.

Eun, B. 2008. Making connections: Grounding professional development in the development theories of Vygotsky. The Teacher Educator 43: 134-155. Doi: 10.1080/08878730701838934.

Gilbert, J. E. and C. A. Swanier. 2008. Learning styles: How do they fluctuate? Institute for Learning Styles Journal 1: 29-39.

Jahreie, C. F. E. Ottesen. 2010. Learning to become a teacher: Participation across spheres for learning. In Cultural-historical perspectives on teacher education and development: Learning to teach, ed. V. Ellis, A. Edwards and P. Smagorinsky, 131-145. London: Routledge.

Johnson, B. and L. Green. 2007. Thinking differently about education support. In Responding to the challenges of inclusive education in southern Africa, ed. P. Engelbrecht and L. Green, 159-174. Pretoria: Van Schaik Publishers.

McIntyre, D. 2009. The difficulties of inclusive pedagogy for initial teacher education and some thoughts on the way forward. Teaching and Teacher Education 25: 602-608.

Nel, M. and M. M. Grosser. 2016. An appreciation of learning disabilities in the South African context, Learning Disabilities: A Contemporary Journal 14(1): 79-92

Oswald, M. M. 2010. Teacher learning for inclusion in a primary school in the Western Cape. Unpublished PhD dissertation. Stellenbosch: Stellenbosch University.

Peters, S. and D. K. Reid. 2009. Resistance in discursive practice: Promoting advocacy in teacher undergraduate and graduate programmes. Teaching and Teacher Education 25: 551-556.

Putnam, R. T. and H. Borko. 2000. What do new views of knowledge and thinking have to say about research on teacher learning? Educational Research 29: 4-15. Doi: 10.3102/ 0013189X029001004.

Sannino, A. 2010. Breaking out of a professional abstraction: the pupil as materialized object for trainee teachers. In Cultural-historical perspectives on teacher education and development: Learning to teach, ed. V. Ellis, A. Edwards and P. Smagorinsky: 146-160. London: Routledge.

Smagorinsky, P., L. S. Cook and T. S. Johnson. 2003. The twisting path of concept development in learning to teach. Center on English Learning and Achievement (CELA) Report Number 16002. Washington, Albany: The National Research Center on English Learning and Achievement, the University of Albany.

Stetsenko, A. and I. M. Arievitch. 2004. The self in cultural-historical activity theory. Reclaiming the 
unity of social and individual dimensions of human development. Theory \& Psychology 14(4): 475-503. Doi: 10.1177/0959354304044921

Walton, E. 2012. Student support through differentiated teaching and learning. In Student support in a diverse classroom: A guide for Foundation, Intermediate and Senior Phase teachers of language and mathematics, ed. E. Nel, M. Nel and A. Hugo, 117-140. Pretoria: Van Schaik Publishers.

Walton, E. and G. Lloyd. 2012. From clinic to classroom: A model of teacher education for inclusion. Perspectives in Education 30(2): 62-70

Warford, M. K. 2011. The zone of proximal teacher development. Teaching and Teacher Education 27: 252-258. Doi: 10.1016/j.tate.2010.08.008

Wassenaar, D. R. 2006. Ethical issues in social sciences research. In Research in practice: Applied methods for the social sciences, ed. M. Terre Blanche, K. Durrheim and D. Painter, 61-79. $2^{\text {nd }}$ Edition. Cape Town: University of Cape Town Press (Pty) Ltd.

Wheelahan, L. 2008. What about knowledge? The deskilling of teachers' work. The Australian Technical and Further Education Teacher Autumn, 2008. 